\title{
Forward Surgery On Operation Telic - Iraq 2003
}

\author{
PJ Parker, SA Adams, D Williams, A Shepherd
}

"A great deal of claptrap has been written about the principles of war surgery...the surgeon at war is faced by certain problems not met with in civilian accident surgery. He has to deal with casualties greater in number and severity, and more varied in type; his operating theatre must be mobile and adaptable to diverse conditions; and he must evacuate the wounded with all possible speed, both to clear the unit and restore its mobility... he must wherever possible, avoid procedures that will prevent the early evacuation of the patient" (1).

\section{ABSTRACT}

Two Air Assault Surgical Groups (AASGs) from 16 Close Support Medical Regiment deployed to Kuwait on Operation Telic in February 2003. Each AASG was comprised of a four-table resuscitation facility, a two table FST and a twin-bedded ITU facility. An A+E Consultant and nurse, an experienced radiographer and laboratory technician with two further RGNs and CMTs provided resuscitation support. Each FST had an orthopaedic and a general surgeon, two anaesthetists and eight operating department practitioners. Further equipment consisted of a Polymobil 111 X-ray unit, a Sonosite 180 ultrasound scanner and an ISTAT gas, haematocrit and electrolyte analyser. 100 units of mixed blood were carried by each AASG.

Fifty-one surgical procedures were performed on thirty one patients. Twenty one of these patients were Iraqi prisoners of war or civilians. Seventeen wound debridements, five amputations, five laparotomies, four insertions of Denham pins with

Lt Col P J Parker RAMC

Email: paul.parker@stees.nhs.uk

Maj S A Adams RAMC

Maj D Williams

$\operatorname{RAMC}(\mathrm{V})$

Col A Shepherd L/RAMC

Parachute Field

Surgical Team, 16 Close Support Medical

Regiment, Goojerat

Barracks, Colchester,

Essex, CO2 7NZ
Thomas splintage for femoral fracture, three external fixations and one axillary artery repair formed the basis of the major cases undertaken. The first field use of activated factor VII by the British Army was successful in the resuscitation of a patient with exsanguinating haemorrhage after an open-book (APC-III) pelvic fracture and a ruptured intrapelvic haematoma. The other cases included eleven manipulations under anaesthetic/application of plaster and four finger terminalisations.
Forward military surgery has a continued role to play on the modern fast moving battlefield. 16 Close Support Medical Regiment normally supports 16 Air Assault Brigade with its remit for expeditionary operations and SF support. Its experience on Op Telic should influence planning for future deployment.

\section{Background}

16 Close Support Medical Regiment (16 CSMR) is responsible for the provision of front-line medical support to the highly mobile 16 Air Assault Brigade and also UKSF. Its light surgical teams are designed to provide an extremely high level of medical and surgical care in austere, arduous and remote environments. It has the ability to deploy by parachute and by rotary-wing or fixed wing insertion. On Operation Telic (The 2003 Gulf War), two Air Assault Surgical Groups (AASGs) from 16 Close Support Medical Regiment deployed to Kuwait in February 2003. During the conflict phase, these two AASGs leapfrogged each other northwards supporting the rapid advance of 16 Air Assault Brigade. This paper examines the cases performed and the lessons learnt during this period.

\section{Equipment}

Each AASG was comprised of a four-table resuscitation facility, a two table Field Surgical Team (FST) and a twin-bedded Intensive Care facility with two additional High Dependency beds. An accident and emergency consultant and nurse, an experienced radiographer and laboratory technician with two further RGNs and Combat Medical Technicians provided resuscitation support. Each FST had an orthopaedic and a general surgeon, two anaesthetists and eight operating department practitioners. Each AASG was independently mobile on 13 light trucks. Further equipment consisted of a Polymobil $111 \mathrm{X}$ ray unit, a Sonosite 180 ultrasound scanner 
and an ISTAT gas, haematocrit and electrolyte analyser. 100 units of mixed blood were carried by each AASG. Tentage in or around buildings was the normal unit configuration (Figure 1).

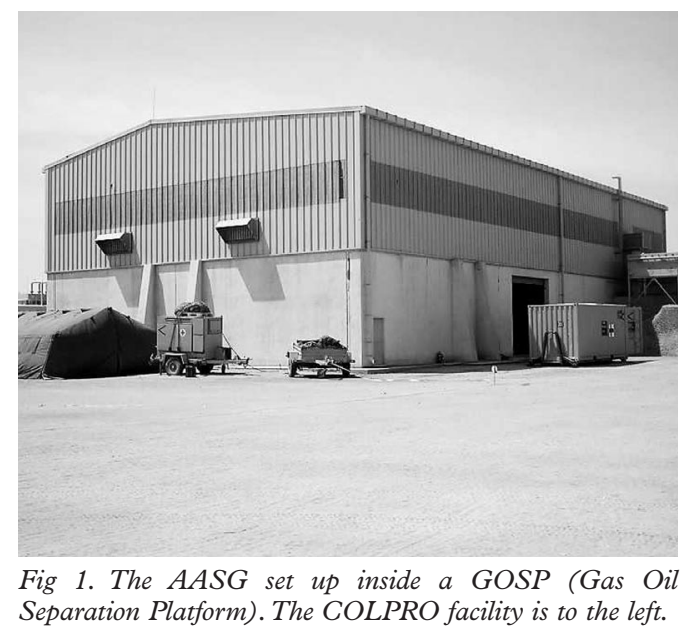

\section{Military Background}

When the war began on March 20th 2003, 23 Squadron was set up in the Brigade tactical assembly area just south of the Kuwait/Iraq border. 19 Squadron was mobile on wheels and ready to move at 15 minutes notice. When 3 Para battle group crossed their start line into Iraq on 22 nd March, 19 Squadron moved with them and set up 40 kilometres north of the border in the southern Rumayliah oilfields. Once they were set up and open, 23 Squadron collapsed and followed 1 Para into the oilfields. During the course of the war, the two squadrons leapfrogged each other northwards supporting 16 Air Assault Brigade as it crossed the Hamar canal and the Euphrates River. By 14th April they reached what were to be their final locations in Maysan province of south-central Iraq on the outskirts of the town of Al-Amarah on the banks of the Tigris River.

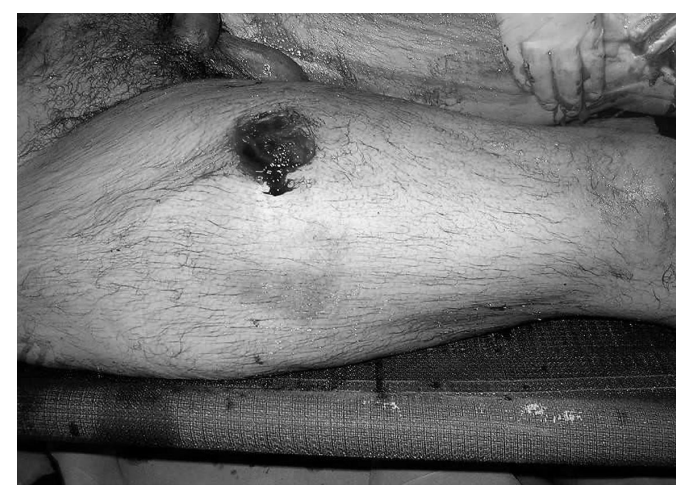

Fig 2a. High energy transfer injury to right thigh showing the exit wound.

\section{Surgical Cases - Summary}

Fifty one surgical procedures were performed within Iraq on thirty one patients. Twenty one of these patients were Iraqi POWs or civilians. Seventeen wound debridements (Figures 2a, 2b, 2c, 2d), five laparotomies, five amputations, four insertions of Denham pins with Thomas splintage for femoral fracture, three external fixations (two tibial, one pelvic) and one axillary artery repair form the basis of the major cases undertaken between 20th March and 25th April 2003. The other cases included eleven manipulations under anaesthetic/application of plaster and four finger terminalisations.

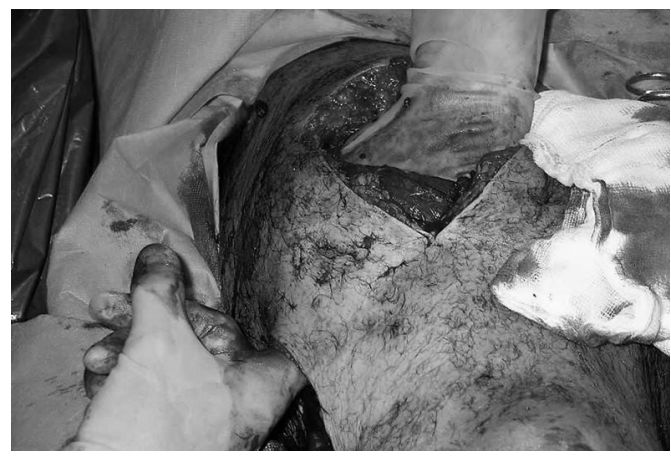

Fig 2b. Initial debridement of wound cavity showing extent of tissue damage.

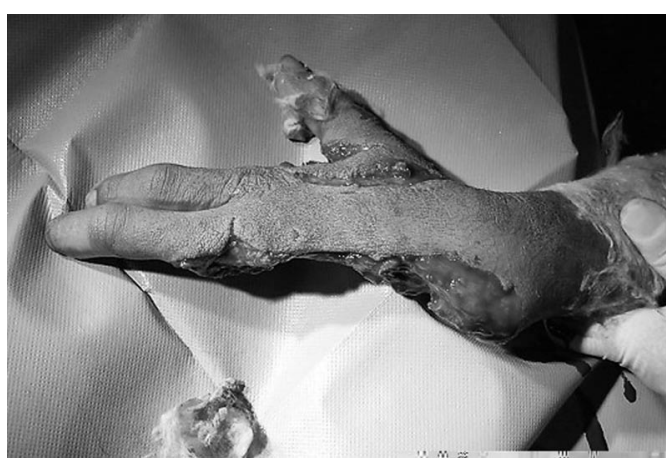

Fig 2c. Blast injury to left hand, partly treated at a local Iraqi factility.

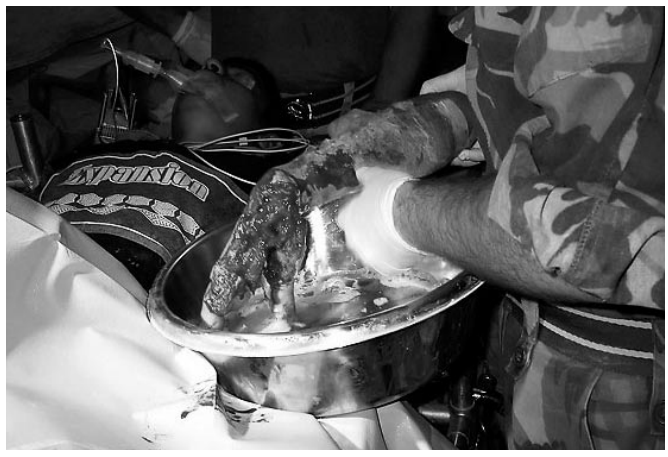

Fig $2 d$. Simple cleaning using bottled mineral water then debridement.

\section{Major Surgical Cases - Details}

\section{Laparotomies}

1. An Iraqi Fedayeen in his late 30's sustained a shrapnel injury to both sides of his chest. A left haemothorax and right pneumothorax were noted on chest X-ray, $500 \mathrm{ml}$ blood drained on insertion of a left chest drain. There was a shrapnel wound to the left elbow. FAST (Focussed Abdominal Sonography in Trauma) scan was (falsely) positive in the hepato-renal pouch. No intraabdominal injuries were found at laparotomy (Figure 3). 


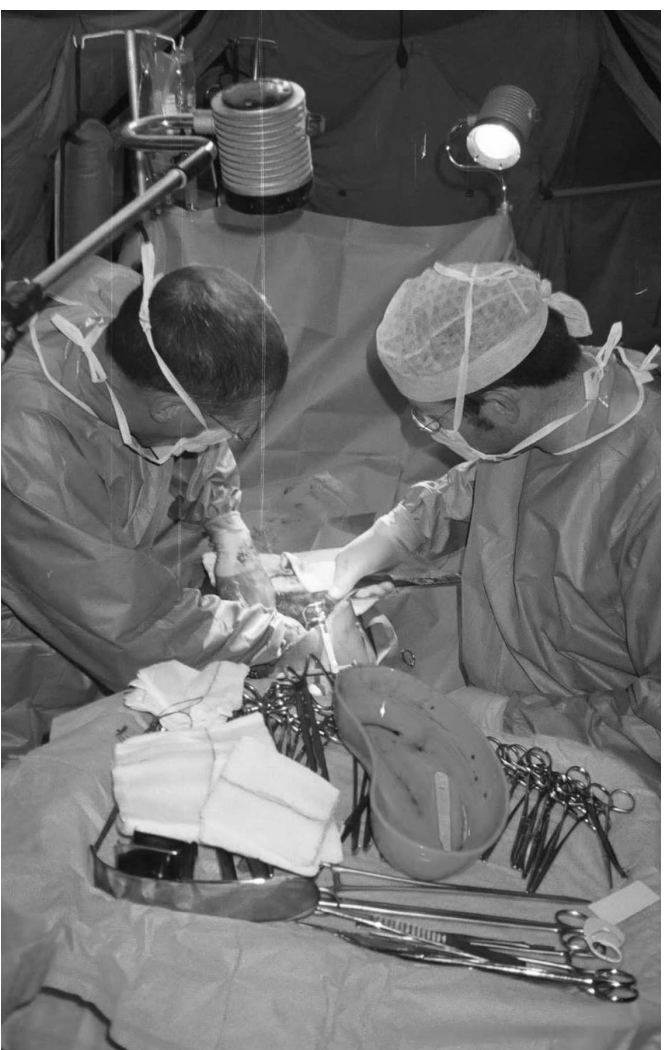

Fig 3. Laparotomy One for suspected intra-abdominal haemorrhage on the McVicar Table.

2. An Iraqi Fedayeen in his late 30's sustained shrapnel injuries to his right lateral chest wall, deep penetrating injury to both buttocks and right tibia with a compound proximal tibial fracture. FAST scan was negative. He was initially tachycardic and hypotensive. Laparotomy was negative.

3. An Iraqi civilian aged 15 sustained a close range abdominal gunshot wound with a large entry wound on the anterior abdominal wall with protruding omentum. Penetrating wounds to the anterior and posterior walls of the stomach were repaired. A penetrating wound of the pancreas was seen, the bleeding was controlled and the pancreatic bed drained.

4. A US soldier aged 20 was involved in a side impact road traffic accident (RTA). Compound fractures of the left femur and tibia and a closed fracture of the left humerus were seen. His abdomen was diffusely tender and he was shocked on admission to the AASG. The main cause of his hypotension was initially uncertain. FAST scan was positive for fluid in the splenic region and showed clear splenic damage (Figure 4). Laparotomy confirmed a ruptured spleen and a splenectomy was performed. His wounds were debrided, the tibia externally fixed, and a Denham traction pin was placed in the distal femur and a Thomas splint applied. The humerus was immobilized in a plaster cast. Postoperatively, he was completely stable and was transferred the next day to a US facility.

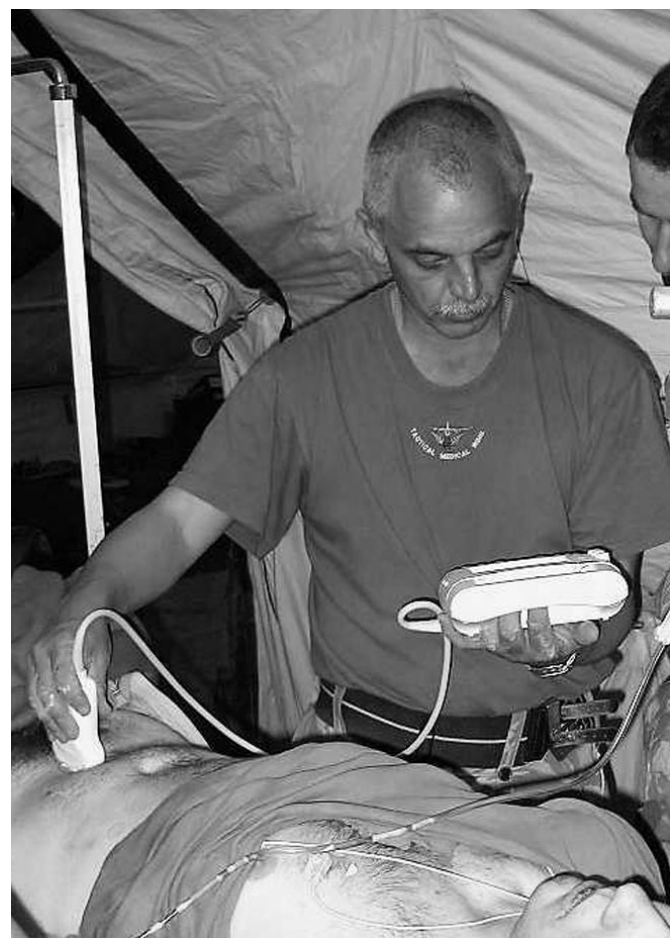

Fig 4. Laparotomy Four: FAST scanning for a ruptured spleen in a patient with multiple long bone fractures.

5. A UK soldier age 26 was involved in roll over RTA and ejected. He sustained an APC-III(2) injury to his pelvis. He was hypotensive and tachycardic on admission. Initial FAST scan showed a contained intrapelvic haematoma. A Hoffmann 2 pelvic external fixator was applied with some transient stabilization of his condition, however he then continued to deteriorate. FAST scan showed accumulating intraperitoneal free fluid from a ruptured retroperitoneal haematoma. His condition became critical. No helicopters could fly north because of sandstorms to the south. Laparotomy, pelvic packing, aortic cross clamping, selective iliac clamping and finally ligation of the right internal iliac artery were required to control his bleeding. A retrograde urethrogram showed disruption of the membranous urethra. In total 29 units of blood were required to resuscitate this patient including 9 units of blood from a fresh donor panel, FFP and activated Factor 7.

\section{Amputations}

A six-year-old Iraqi child who had been injured in an explosion 24 hours previously presented to the unit. His wounds had only received basic dressings. The right foot had been completely destroyed. An attempt was made to perform an initial low tibial amputation but the muscle in the superficial posterior compartment was dead further up the calf necessitating a higher amputation than the normal paediatric site of election. The left first ray had also been badly damaged and this was removed. (Figures $5 a, 5 b)$ 


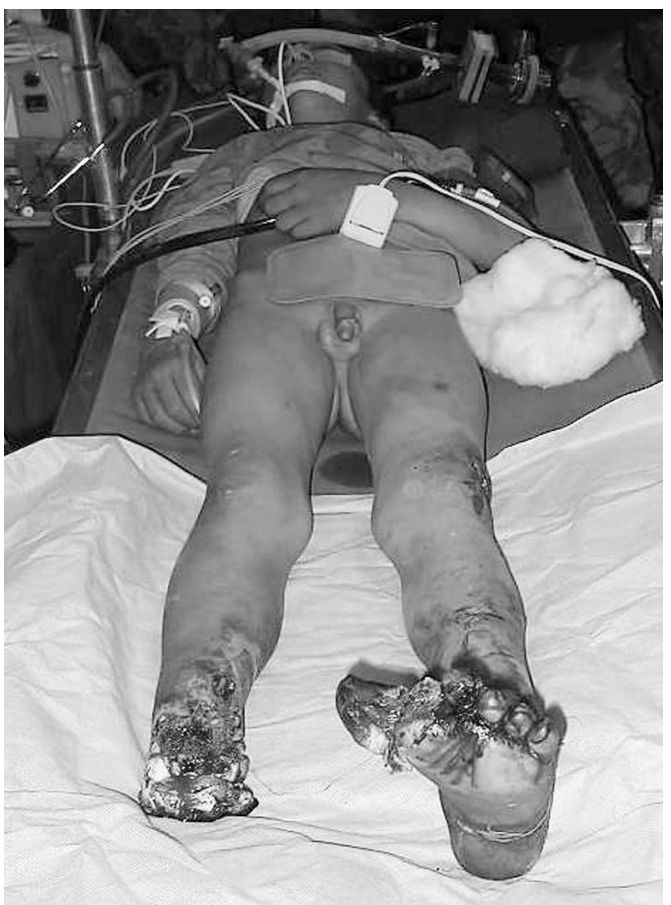

Fig 5a. Blast Injury to both lower limbs in a 6 year old Iraqi boy.

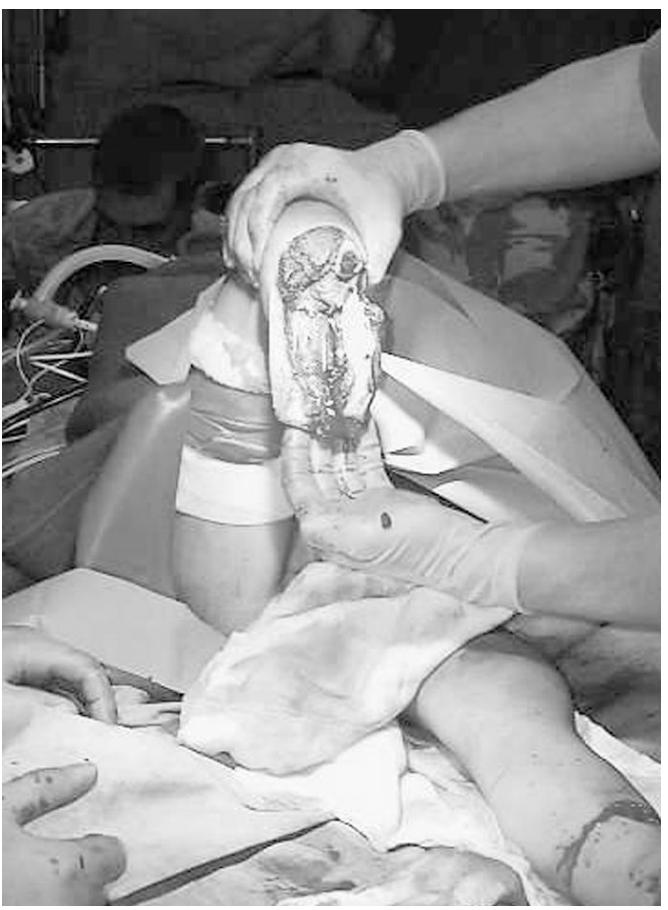

Fig 5b. Below knee amputation for unsalvageable limb injury from $5 a$.

A twenty-year-old Iraqi male sustained injuries to his right hand when a grenade exploded prematurely causing extensive damage to the right hand and forearm. $\mathrm{He}$ also sustained a wound to the left forearm and a penetrating right eye injury. There was extensive damage to the deep flexor muscles of the forearm with relative sparing of the superficial muscles necessitating amputation at mid forearm level. On the left side extensive swelling occurred with vascular compromise and exploration of the vessels with compartmental fasciotomies was required.

Two further below knee amputations were performed for anti-personnel mine injuries.

\section{Arterial Repair}

A young Iraqi male sustained a gunshot wound to the left shoulder. An entry wound in the superior aspect of the shoulder and exit wound in the left posterior chest was seen. Approximately $200 \mathrm{mls}$ of blood drained from a chest tube. A pulseless left arm with evidence of a brachial plexus injury was noted. The proximal axillary vessels were exposed and controlled as outlined in the Definitive Surgical Trauma Skills Manual (3). The wound was explored and the axillary vein found to be completely transected and was therefore ligated. The second part of the axillary artery was partially transected with a small bridge inferiorly. Repair was carried out with a $5 / 0$ prolene suture and circulation to the limb restored. The trunks of the brachial plexus were identified as intact.

\section{Discussion}

\section{History}

Forward surgery has been employed on most of the major battlefields of the twentieth century. In World War II, the parachute drops in support of the Rhine crossings were supported by 224 and 225 Parachute Field Ambulances and 195 Airlanding Field Ambulance in a forward surgical role. As in Operation Market Garden, rearward evacuation was not initially possible and casualties had to be held forward. During Wavell's desert campaign of 1940, captured Italian trucks were used to create the "self contained mobile surgical centre", able to attach itself to any casualty clearing station, field dressing station or field ambulance" (1). Only 13 light trucks were required to move the unit - the same number as in an AASG today. In the Falklands war, forward surgical teams were deployed to Teal Inlet and Bluff Cove (4). During the first Gulf War (Operation Granby), forward aggressive surgical teams were successfully used close to the forward edge of the battle area (FEBA) (5). In Afghanistan and other recent counterterrorist operations in remote locations, the (far) forward surgical team was often the sole available surgical resuscitation facility in that country (10).

\section{Manoeuvre}

On the modern mechanized battlefield the FEBA can move over $100 \mathrm{~km}$ in a day. Forward surgical teams must be prepared to be highly mobile. The close medical support of such a campaign requires an understanding of what can and cannot be achieved by forward surgery. Role 3+ facilities or Static Field Hospitals will always be necessary but in theory and practice require at least 7 days to set up or take down. Over wide geographical areas it is generally impractical to ask 200 bed facilities to move every five days. To maintain clinical 
timelines, smaller elements such as AASGs or 10 bedded facilities budded off Field Hospitals, which can be erected in much less time (and with appropriate integral transport), are therefore necessary.

\section{Forward Surgery}

The nature of forward surgery itself alters from hour to hour depending on evacuation availability and timelines. In a remote location where casevac may not be possible for 2-3 days - such as an airfield assault, more definitive surgery must obviously be undertaken. When casevac is robust and air assets immediately available, forward surgery may involve only the placement of a clamp or shunt onto a great vessel; or placement of a damp dressing on the protruding bowel of a stable patient with a penetrating abdominal injury. Forward surgery is, therefore, best defined as a flexible approach to resuscitation surgery ("turning off the tap"), which might include the use of Damage Control Surgery (6), and which when geographically or logistically necessary could extend to more definitive surgery.

\section{Blood}

The forward availability of blood as resuscitation fluid remains paramount. Across both AASGs during Operation Telic, 119 units of blood were cross-matched and 66 units transfused into 19 patients. In accordance with recent research and best evidence (7) a hypotensive approach to resuscitation in trauma was followed. Only once the source of the bleeding had been identified and controlled, did resuscitation continue to a normotensive, normovolaemic state. In one patient who required 29 units of blood, such an approach was felt to be life saving. It was also noted that civilian casualties whose untreated wounds had often oozed for 24 hours or more before admission were often profoundly anaemic. Perioperative blood transfusion allowed their surgical debridements to be performed more safely.

\section{Antibiotics}

All non-infected fragment wounds less than $1 \mathrm{~cm}$ in size were treated conservatively with antibiotics and dressings and these patients have not been included in the data presented here (8). Those patients with penetrating war wounds all received intravenous Benzylpenicillin $1.2 \mathrm{~g}$ as prophylaxis against clostridial infection. In addition all limb wounds were given flucloxacillin $1.0 \mathrm{~g}$. In abdominal wounds, $1.5 \mathrm{~g}$ of cefuroxime and $500 \mathrm{mg}$ metronidazole were added. Head injuries were given $1 \mathrm{~g}$ of chloramphenicol. Coalition soldiers were given a $0.5 \mathrm{ml}$ tetanus toxoid booster; Iraqi civilians and POWs were given 250 units of tetanus immunoglobulin. No adverse reactions were noted.

\section{Imaging}

Focused Abdominal Sonography in Trauma (FAST) scanning was performed as part of the ATLS survey on all patients where closed abdominal injury was suspected. A hand held Sonosite 180 with power Doppler and a 3.5 $\mathrm{MHz}$ probe were used. The Sonosite 180 weighs only $2.4 \mathrm{Kg}$ and measures only $34 \mathrm{x}$ $20 \times 6 \mathrm{~cm} .23$ Squadron had the benefit of an ultrasound-trained radiographer. In 19 Squadron, two military consultants, who had trained in the technique, performed the scans. FAST used by trained surgeons has a sensitivity of $83 \%$, a specificity of $87 \%$ and an accuracy of $85 \%$ (9). FAST scanning clearly identified a ruptured spleen (Figure 4) and a retroperitoneal haematoma in two patients and was responsible for the decision to proceed to laparotomy in these patients. In two unconscious patients with severe head injuries and multiple long bone fractures, FAST was used to exclude any abdominal injury prior to transfer. FAST using the Sonosite 180 is man-portable and can be performed by suitably trained medical staff. All forward surgical units should have the means and training to perform FAST.

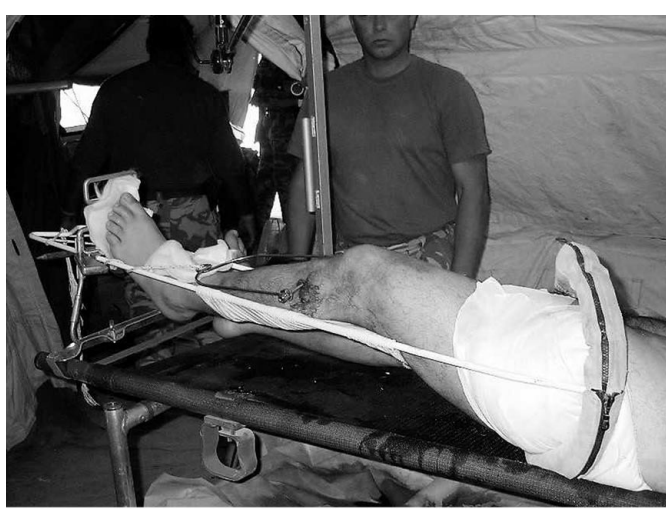

Fig 6. Correct application of a Thomas Splint for a femoral fracture on a GS stretcher.

\section{External Fixation}

Inexperienced surgeons have been previously tempted to apply external fixators to femoral fractures. Whether open or closed this is unnecessary. In closed fractures, the percutaneous fixator pins contaminate the sterile medullary canal within 48 hours and subsequent infection may then preclude intra-medullary nailing at role 4 (11). In 1915 when the mortality for femoral gunshot wounds was in excess of $75 \%$, Sir Charles Max Page and Colonel Sinclair adapted the Thomas splint (which had previously been designed for treatment of tuberculosis of the knee) to the treatment of these femoral war wounds. The mortality fell to $20 \%$ - even in that pre-antibiotic era. The judicious use of a correctly applied Thomas splint via either a well applied trans-tibial or trans-femoral pin (Figure 6) cannot currently be bettered for patient care and transfer. If a long journey is anticipated, the whole of the splint can be encased in plaster - the Tobruk splint of 1941 (1). 


\section{Casevac}

Transfer to rôle 3 was to be either by helicopter or wheeled (BFA) ambulance. Prior to the start of the campaign it was envisaged that $\mathrm{P} 1$ and $\mathrm{P} 2$ casualties would transfer by helicopter and $\mathrm{P} 3$ s by road or as space-fillers in helicopters. However, the UK does not currently have any dedicated casevac ("dust-off") helicopters and casevac requests depend on the occasional availability of a support helicopter which then has to be rerôled. In the early stages of the campaign there was also a threat of attack on road ambulances by irregular Iraqi forces. Adverse light and weather conditions were other confounding factors. This meant that there were occasions where patients had to be held at the AASG when immediate transfer would have been preferable. Only $50 \%$ of helicopter casevac requests were ultimately fulfilled. As previously stated, the indications for the type and degree of intervention at role $2+$ may vary enormously depending on perceived casevac timelines to role 3 . If the UK had a dedicated, all weather helicopter casevac evacuation squadron, there would be no need to site surgical units forward on the classic mechanized warfare battlefield.

\section{Personnel}

Surgery at this level should be completely and solely consultant based. However, this does not preclude the attachment of SHOs and SpRs to such units as supervised trainees. This also applies to the anaesthetic and $\mathrm{A}+\mathrm{E}$ positions. All the clinicians must be able to live and survive, not necessarily in comfort, in austere environments and still be able to perform on demand. Possession of satisfactory field skills in addition to requisite clinical skills is mandatory.

\section{Training}

All surgical and support staff should have recent experience of the twice yearly Definitive Surgical Trauma Skills Course run at the Royal College of Surgeons of England. The same applies to the ICRC War Surgery course held yearly in Guildford. The Royal Defence Medical College runs a number of courses and practical workshops each year on; war surgery, external fixation, emergency maxillofacial surgery, crisis neurosurgery and military obstetrics and gynaecology. All deploying military surgeons should attend these courses regularly. Without such exposure there is the temptation, seen at the beginning of every war, to perform limited and inadequate wound debridements and surgical procedures which are inappropriate. The role of the Speciality Defence Consultant Adviser in the wartime theatre must be that of roving clinical governance. This is a rôle that cannot satisfactorily be undertaken from the UK. Lessons learnt from previous wars must be retained in an institutional memory for the next conflict.

\section{Summary}

The principles of forward surgery have remained unchanged since the Second World War. The sooner the unstable patient undergoes resuscitation surgery, the better. Bleeding and peritoneal spillage are controlled as soon as possible. Soft tissue wounds should be appropriately debrided within six hours. Where lines of communication are short and timelines easily fulfilled, a policy of "scoop and run" should be undertaken and forward surgical units overflown by dedicated casevac helicopters to role 3 hospitals. However, as distances extend and lines of communication are disrupted or unacceptably extended then the appropriately staffed, trained and supported, highly mobile forward surgical unit comes into its own.

\section{Conclusion}

Forward military surgery has a continued rôle to play in the modern fast moving conflict. Units can be deployed rapidly from the UK - often within twenty-four hours and be working within one hour of arrival in location. The experiences of the AASGs of 16 Close Support Medical Regiment on Op Telic should influence planning for future operations.

\section{References}

1. Watts JC. Surgeon at War. Digit Books London, 1955.

2. Young JW, Burgess AR, Brumback RJ, Poka A. Pelvic fractures: Value of plain radiography in early assessment and management. Radiology 1986; 160:445-51.

3. Definitive Surgical Trauma Skills Manual. Eds Botha P, Brooks A, Loosemore T. 2002 The Royal College of Surgeons of England.

4. Jackson DS, Batty CG, Ryan JM, McGregor WSP. The Falklands War: Army Field Surgical Experience. Ann R Coll Surg 1983, 65:281-285.

5. J Hull - Personal Communication.

6. Hirshberg A, Mattox KL. 'Damage control' in trauma surgery. Br f Surg 1993;80:1501-2.

7. Bickell WH, Wall MJ Jr, Pepe PE, Martin RR, Ginger VF, Allen MK, Mattox KL. Immediate versus delayed fluid resuscitation for hypotensive patients with penetrating torso injuries. $N$ Engl $\mathcal{f}$ Med 1994 27;331(17):1105-9.

8. War Wounds: Basic Surgical Management 1994 ICRC, Geneva, Switzerland.

9. Rozycki GS, Ballard RB, Feliciano DV, Schmidt JA, Pennington SD Surgeon-performed ultrasound for the assessment of truncal injuries: lessons learned from 1540 patients. 1998 Ann Surg. 1998 Oct;228:557-67.

10. Parker PJ, Becker G, Clasper J, Sargeant ID. Far Forward Surgery and the Casualty Evacuation Chain: Afghanistan 2001 JBJS 2003 85-B Supp II.

11. Clasper JC, Stapley SA, Bowley DM, Kenward CE, Taylor V, Watkins PE. Spread of infection, in an animal model, after intramedullary nailing of an infected external fixator pin track. f Orthop Res. 2001;19:155-9. 